\title{
What Does a Shoulder MRI Cost the Consumer?
}

\author{
Robert W. Westermann MD, Cameron Schick MD, Christopher M. Graves MD, \\ Kyle R. Duchman MD, Stuart L. Weinstein MD
}

Received: 3 June 2016/Accepted: 16 November 2016/Published online: 28 November 2016

(C) The Association of Bone and Joint Surgeons (B) 2016

\begin{abstract}
Background More than 100 MRIs per 1000 inhabitants are performed in the United States annually, more than almost every other country. Little is known regarding the cost of obtaining an MRI and factors associated with differences in cost.

Questions/Purposes By surveying all hospital-owned and independent imaging centers in Iowa, we wished to determine (1) the cost to the consumer of obtaining a noncontrast shoulder MRI, (2) the frequency and magnitude of discounts provided, and (3) factors associated with differences in cost including location (hospital-owned or independent) and Centers for Medicare \& Medicaid Services designation (rural, urban, and critical access).
\end{abstract}

Each author certifies that he or she, or a member of his or her immediate family, has no funding or commercial associations (eg, consultancies, stock ownership, equity interest, patent/licensing arrangements, etc) that might pose a conflict of interest in connection with the submitted article.

All ICMJE Conflict of Interest Forms for authors and Clinical Orthopaedics and Related Research ${ }^{\circledR}$ editors and board members are on file with the publication and can be viewed on request.

Each author certifies that his or her institution approved or waived approval for the human protocol for this investigation and that all investigations were conducted in conformity with ethical principles of research.

Electronic supplementary material The online version of this article (doi:10.1007/s11999-016-5181-9) contains supplementary material, which is available to authorized users.

R. W. Westermann, C. Schick, C. M. Graves,

K. R. Duchman $(\bowtie)$, S. L. Weinstein

Department of Orthopaedics and Rehabilitation, University of Iowa, 200 Hawkins Dr., 01008 JPP, Iowa City, IA 52242, USA

e-mail: kyle-duchman@uiowa.edu
Methods There were 71 hospitals and 26 independent imaging centers that offered MRI services in Iowa. Each site was contacted via telephone and posed a scripted request for the cost of the technical component of a noncontrast shoulder MRI. Radiologists' reading fees were not considered. Statistical analysis was performed using standard methods and significance was defined as a probability less than 0.05 .

Results The mean technical component cost to consumers for an MRI was USD $1874 \pm$ USD 694 (range, USD 500USD 4000). Discounts were offered by $49 \%$ of imaging centers, with a mean savings of $21 \%$. Factors associated with increased cost include hospital-owned imaging centers (USD $2062 \pm$ USD 664 versus USD $1400 \pm$ USD 441 at independent imaging centers; $\mathrm{p}<0.001$; mean difference, USD 662; 95\% CI, USD 351-USD 893) and rural imaging centers, unless designated as a critical access hospital (USD $2213 \pm$ USD 668 versus USD $1794 \pm$ USD $680 ; \mathrm{p}=0.0202$; mean difference, USD 419; 95\% CI, USD 66-USD 772).

Conclusions In Iowa, the cost to the consumer of a shoulder MRI is significantly less at independent imaging centers compared with hospital-owned centers. Referring physicians and healthcare consumers should be aware that there may be substantial price discrepancies between centers that provide advanced imaging services.

Level of Evidence Level IV, Economic and decision analysis.

\section{Introduction}

Spending on health care in the US by government, commercial payers, and patients is expected to reach USD 5.4 trillion by 2024 [15]. Diagnostic imaging in all forms represents a substantial share of that spending [2]. 
Previous efforts to control costs, such as the Stark Laws, have focused on banning referrals by physicians to facilities in which they have a direct financial interest $[1,7,18,20,21]$. Changes in insurance coverage, including the Patient Protection and Affordable Care Act (PPACA), commonly called the Affordable Care Act or "Obamacare", have emphasized "bending the cost curve down" by asking or forcing patients to assume more of the costs of care $[27,29]$. This has been done by narrowing networks of approved providers, higher deductibles, and increased scrutiny by payers of requested referrals [25]. In addition, despite the intentions of the PPACA, a large proportion of the population aged 18 to 64 years remains uninsured $[19,28]$. As a result, patients and providers have a keen interest in obtaining the best value for healthcare dollars spent. Finally, policymakers have long assumed that price transparency will result in competition between imaging centers with the potential for open market driven decreases in cost for these services.

To our knowledge, no studies have evaluated and quantified the cost to consumers for obtaining an MRI. Using a noncontrast MRI of the shoulder as an example of an electively performed procedure, we asked the following: (1) the cost to the consumer of obtaining a noncontrast shoulder MRI, (2) the frequency and magnitude of discounts provided, and (3) factors associated with differences in cost including setting (hospital-owned or independent) and Centers for Medicare \& Medicaid Services (CMS) designation (rural, urban, and critical access).

\section{Methods}

Using data from the Iowa Hospital Association (IHA) [14], a list of hospitals in the state that provide outpatient MRI services was obtained. Using similar IHA data, a list of orthopaedic physicians practicing in Iowa was obtained, and physicians were grouped by practice. Each orthopaedic practice was called and asked whether they provided independent MRI services and were subsequently classified as independent imaging centers. Using IHA data, we identified 131 hospitals in Iowa, of which 75 provided shoulder MRI services. Similarly, 58 orthopaedic practices were identified, 26 of which offered MRI services at independent imaging centers. Hospitals and independent imaging centers providing MRI services then were contacted and read a scripted query (Appendix 1. Supplemental material is available with the online version of CORR ${ }^{\circledR}$ ) regarding the cost of a noncontrast MRI of the right shoulder (Current Procedural Terminology code 73221) for a hypothetical patient who was paying for the service in cash. Imaging centers were asked if discounts could be provided for full cash payment up front. The cost requested was for the technical component only without a formal radiology reading. Facility fees, which allow a healthcare organization to bill patients an additional service charge for the patient's use of hospital facilities and equipment, also were not considered. The cost for the MRI, without reading fees and with discounts applied, was considered the "best price". For this study, all references will be from the healthcare consumer perspective and will be referred to as costs.

In all cases, it was assumed that the hypothetical patient was paying cash up front, and all discounts were applied, thus the "best price" scenario was recorded for each imaging center.

Hospitals were classified based on their status as "rural", "urban", "critical access hospital", or "rural referral center" based on the CMS criteria [4].

Standard statistical tests, including chi-square for categorical variables and Student's t-test for continuous variables, were used. All monetary values were reported in USD. The level of significance for all portions of the analysis was set at a probability less than 0.05 . All statistical analyses were performed using Microsoft ${ }^{\circledR}$ Excel $^{\circledR}$ (Microsoft Corporation, Redmond, WA, USA).

\section{Results}

In total, 68 of 75 hospitals and 26 of 26 independent centers were able to provide the cost of obtaining an MRI. The mean best-price technical cost to the consumer for a shoulder MRI was USD $1874 \pm$ USD 694 (range, USD 500-USD 4000). The mean technical cost for an MRI was greater at hospital-owned imaging centers than at independent imaging centers (USD $2062 \pm$ USD 664 versus USD $1400 \pm$ USD 511; mean difference, USD 662; 95\% CI, USD 351-USD 893; p < 0.001) (Table 1).

\section{Frequency and Magnitude of Offered Discounts}

Several hospital-owned and independent imaging centers offered to negotiate the price of the shoulder MRI based on payment terms, including immediate cash payment or full payment within 30-90 days. These offers were highly variable and not uniformly available from either hospital or independent imaging centers. Overall, 49\% (49/101) of imaging centers were able to offer discounts for up-front cash payments. Only $34.6 \%$ (nine of 26) of independent imaging centers offered a discount. The mean discount, when offered, by an independent imaging center was $25 \%$ of the originally quoted cost (range, 15\%-30\%). The majority of hospitals, 52\% (39/75), offered imaging discounts for immediate cash payments. The mean discount, when offered, was $21 \%$ (range, $5 \%-62 \%$ ). 
Table 1. Comparison of costs for shoulder MRI at hospital-owned and independent imaging centers

\begin{tabular}{|c|c|c|c|c|}
\hline Community type & Hospital owned & Independent imaging center & Mean difference $(95 \% \mathrm{CI})$ & $\mathrm{p}$ Value \\
\hline \multicolumn{5}{|l|}{ All } \\
\hline Surveyed centers, number $(\%)$ & $68 / 75(91)$ & $26 / 26(100)$ & $662(351-893)$ & $<0.001$ \\
\hline Mean cost, USD & $2062 \pm 664$ & $1400 \pm 511$ & & \\
\hline \multicolumn{5}{|l|}{ Urban } \\
\hline Surveyed centers, number $(\%)$ & $19 / 23(83)$ & 18/18 (100) & $769(405-1133)$ & 0.002 \\
\hline Mean cost, USD & $2061 \pm 844$ & $1292 \pm 441$ & & \\
\hline \multicolumn{5}{|l|}{ Critical access hospital } \\
\hline Surveyed centers, number $(\%)$ & $38 / 39(97)$ & $1 / 1(100)$ & $1155\left(\mathrm{NA}^{*}\right)$ & $\mathrm{NA}^{\ddagger}$ \\
\hline Mean cost, USD & $1925 \pm 544$ & 770 & & \\
\hline \multicolumn{5}{|l|}{ Rural and rural referral } \\
\hline Surveyed centers, number $(\%)$ & $11 / 13(85)$ & 7/7 (100) & $838(290-1386)$ & 0.005 \\
\hline Mean cost, USD & $2539 \pm 506$ & $1701 \pm 579$ & & \\
\hline
\end{tabular}

USD $=$ United States Dollars; ${ }^{*}$ Not Available

\section{Factors Associated with Increased MRI Cost}

\section{Hospital-Owned MRIs}

The mean technical cost of an MRI was greater at hospitalowned imaging centers than at independent imaging centers (USD $2062 \pm$ USD 664 versus USD $1400 \pm$ USD 441; mean difference, USD 662; 95\% CI, USD 351-USD $893 ; \mathrm{p}<0.001)$.

\section{CMS Designation}

The costs of imaging offered in centers designated as either rural or rural-referral imaging centers were greater than those offered at critical access or urban centers (USD $2213 \pm$ USD 668 versus USD $1794 \pm$ USD 680; $\mathrm{p}=0.0202$; mean difference, USD 419; 95\% CI, USD 66USD 772). The cost of imaging offered in urban centers was greater in hospital-owned facilities compared with independent imaging centers (USD $2061 \pm$ USD 844 versus USD $1292 \pm$ USD 441; mean difference, USD 769; 95\% CI, USD 405-USD 1133; $\mathrm{p}=0.002$ ). The cost of imaging offered in rural centers was greater in hospitalowned facilities compared with independent imaging centers (USD $2539 \pm$ USD 506 versus USD $1701 \pm$ USD 579; mean difference, USD 838; 95\% CI, USD 290-USD $1386 ; \mathrm{p}=0.005)$.

\section{Discussion}

Rising healthcare costs continue to be a topic of interest for policymakers, payers, physicians, and patients in the United States. Advanced diagnostic imaging, including MRI, comprises a substantial portion of healthcare expenditures, and further study of factors related to imaging costs is warranted. Imaging costs appear to vary greatly; however, this information is not readily available to consumers. This lack of transparency may be contributing to increased costs at certain centers offering MRI services and are of upmost interest to the healthcare consumer. Our study determined that the cost of a shoulder MRI varies by $800 \%$, with quoted prices ranging from USD 500 to USD 4000 in Iowa. The mean cost of a shoulder MRI was USD 1874 in Iowa. The cost of a shoulder MRI was lower at independent imaging centers regardless of geographic location. Urban or critical access hospital imaging facilities also were associated with lower costs compared with the cost at imaging facilities in rural or rural referral centers. Several of these findings warrant further discussion.

This study has several limitations. We looked at one state, Iowa, and the findings presented here may not be generalizable at the national level. However, the per capita expenditure on health care in Iowa is close to the mean for the United States as a whole, and thus represents a reasonable model for broader discussion [5]. Further, our study model was based on a cash-paying healthcare consumer who most closely resembles an under- or uninsured Iowan and may be less generalizable to insured patient populations. However, insured patients who have healthcare deductibles equal to or higher cash prices at the lower end of the price spectrum than we presented here also may be affected substantially by these costs. The quality of the MRI, number of sequences offered, and magnet power were not considered and these could further influence cost. We did not evaluate professional fees for radiology interpretation that also may vary across facilities. Additionally, we looked at only independent imaging centers that were affiliated with orthopaedic practices; there is the possibility 
that other third-party and truly "independent" MRI centers may have different pricing structures.

We found substantial variation in consumer costs for a noncontrast shoulder MRI, with a range from USD 500 to USD $4000(800 \%)$. Similar variability has been observed in clinics surveyed for estimates of bunion surgery [30]. Willey et al. [30] found that the total bundled cost for bunion repair ranged from USD 3542 to USD 52207, or a 14.7-fold difference after surveying 12 clinics that could provide a complete bundled estimate for all associated services. Thus, cost variability for healthcare services is not unique to MRI. Some have proposed that a lack of cost transparency for health care as a whole has contributed to large variations and increases in cost, since consumers are unable to compare costs before services [3, 6, 9, 10, 13]. In addition, some facilities may charge a facility fee or service charge for use of MRI machines; while we were unable to analyze this component independently, facility fees may partially explain the discrepancy in price.

We also explored the frequency and magnitude of price discounts offered at hospital-owned facilities and independent imaging centers. Since uninsured or underinsured patients pay a large percentage of their healthcare expenses out of pocket, as do those with high-deductible insurance plans $[12,24]$, payment strategies that minimize costs would be of significant benefit. We found that independent imaging centers and hospital-owned facilities provided discounts for patients willing to pay cash up front. This was offered more frequently by hospital-owned facilities than independent imaging centers, with discounts ranging from $5 \%$ to $62 \%$. Given the high degree of variability in the frequency and magnitude of discounts offered for MRI services, it may be advantageous for under- and uninsured patients to obtain multiple price quotes from facilities offering MRI services to obtain the best value. Furthermore, price transparency may lead to competition between imaging centers and an overall decrease in charges that may be observed at the consumer level $[3,6,9,10]$.

Finally, we looked at factors associated with cost differences. Mitchell [20] expressed concern that physicianowned facilities, such as independent imaging centers, might charge more because of potential financial conflict. This concern also provides the basis for the Stark Laws. However, in another study using Medicare claims data, availability of on-site MRI offered by orthopaedic surgery group practices did not lead to an increase in MRI utilization [21]. Higgins et al. [13] evaluated costs associated with common clinical services using claims data from an employer-sponsored health insurance population. The most striking disparity was a $258 \%$ increase in cost for chest radiographs taken in a hospital setting compared with a physician office setting [13]. Further, there has been a shift in outpatient imaging services from independent facilities to hospitals [23]. In the current study, we found that technical charges for a noncontrast shoulder MRI were $32 \%$ less at independent imaging centers compared with the cost at hospital-owned facilities. This may be explained by the lack of facility fees at independent centers, along with the ability to more expeditiously perform certain studies. Next, we found geographic variations in costs by comparing urban, rural, and critical access hospital status as defined by the CMS [4]. Previous studies have suggested that access to care for advanced imaging is a concern for rural and critical access hospitals [16, 17, 22], which may be directly attributable to the relatively high cost of purchasing and maintaining advanced imaging modalities in low-utilization areas [26]. Urban-rural discrepancies in the orthopaedic workforce have been noted previously, with fewer orthopaedic surgeons practicing in rural areas of the country which might affect access to quality orthopaedic care in these areas [11]. We found that shoulder MRI performed at rural or rural referral centers were associated with higher charges than the same study performed at urban imaging centers or critical access hospitals. Charges at independent imaging centers were consistently lower than at hospital-owned facilities regardless of geographic location and urban-rural classification. We note that increased MRI costs at rural imaging centers may indirectly limit access for patients with high out-of-pocket healthcare expenses.

Use of medical imaging contributes substantially to our nation's expanding healthcare expenditure [8]. In the current study, we found that the costs associated with obtaining a shoulder MRI in Iowa were highly variable, ranging from USD 500 to USD 4000, with consistently lower costs quoted at independent imaging centers. Additionally, MRI obtained at an urban or critical access hospital was associated with decreased costs compared with costs at imaging facilities with rural designations. Owing to the high variability in costs, efforts to improve price transparency may better guide the increasing number of individuals with large deductibles [25] and their referring providers to imaging centers that provide the best value for their healthcare dollar.

\section{References}

1. Amrhein TJ, Lungren MP, Paxton BE, Srinivasan R, Jung SH, Yu M, Eastwood JD, Kilani RK. Journal Club: Shoulder MRI utilization: relationship of physician MRI equipment ownership to negative study frequency. AJR Am J Roentgenol. 2013;201:605-610.

2. Beinfeld MT, Gazelle GS. Diagnostic imaging costs: are they driving up the costs of hospital care? Radiology. 2005;235:934-939.

3. Berwick DM. Commentary: same price, better care. BMJ. 2002;324:142-143.

4. Centers for Medicare and Medicaid Services. Critical Access Hospitals Center. Available at: https://www.cms.gov/Center/ 
Provider-Type/Critical-Access-Hospitals-Center.html. Accessed June 3, 2016.

5. Centers for Medicare and Medicaid Services. NHE Fact Sheet. Available at: https://www.cms.gov/research-statistics-data-andsystems/statistics-trends-and-reports/nationalhealthexpenddata/nhefact-sheet.html. Accessed November 15, 2016.

6. Dixon J. Commentary: funding is not the only factor. BMJ. 2002;324:142.

7. Emanuel E, Tanden N, Altman S, Armstrong S, Berwick D, de Brantes F, Calsyn M, Chernew M, Colmers J, Cutler D, Daschle T, Egerman P, Kocher B, Milstein A, Oshima Lee E, Podesta JD, Reinhardt U, Rosenthal M, Sharfstein J, Shortell S, Stern A, Orszag PR, Spiro T. A systemic approach to containing health care spending. N Engl J Med. 2012;367:949-954.

8. Emanuel EJ, Fuchs VR. The perfect storm of overutilization. JAMA. 2008;299:2789-2791.

9. Enthoven AC. Commentary: Competition made them do it. BMJ. 2002;324:143.

10. Feachem RG, Sekhri NK, White KL. Getting more for their dollar: a comparison of the NHS with California's Kaiser Permanente. BMJ. 2002;324:135-141.

11. Fu MC, Buerba RA, Gruskay J, Grauer JN. Longitudinal urbanrural discrepancies in the US orthopaedic surgeon workforce. Clin Orthop Relat Res. 2013;471:3074-3081.

12. Grande D. Sticker shock: the experience of a health care consumer. Ann Fam Med. 2016;14:270-272.

13. Higgins A, Veselovskiy G, Schinkel J. National estimates of price variation by site of care. Am J Manag Care. 2016; 22:e116-121.

14. Iowa Hospital Association. Iowa Hospital Location Map with IHA Districts. Available at: https://www.ihaonline.org/Portals/0/ Files/auxvol/IHA\%20District\%20Map\%20-\%20updated\%2020122.pdf. Accessed June 3, 2016.

15. Keehan SP, Cuckler GA, Sisko AM, Madison AJ, Smith SD, Stone DA, Poisal JA, Wolfe CJ, Lizonitz JM. National health expenditure projections, 2014-24: spending growth faster than recent trends. Health Aff (Millwood). 2015;34:1407-1417.

16. Khaliq AA, Deyo D, Duszak R Jr. The impact of hospital characteristics on the availability of radiology services at critical access hospitals. $J$ Am Coll Radiol. 2015;12:1351-1356.

17. Khaliq AA, Nsiah E, Bilal NH, Hughes DR, Duszak R Jr. The scope and distribution of imaging services at critical access hospitals. J Am Coll Radiol. 2014;11:857-862.
18. Levin DC, Rao VM, Parker L, Frangos AJ, Sunshine JH. Ownership or leasing of MRI facilities by nonradiologist physicians is a rapidly growing trend. $J$ Am Coll Radiol. 2008;5:105-109.

19. McCarthy M. A quarter of US adults with health insurance are underinsured, report finds. BMJ. 2015;350:h2786.

20. Mitchell JM. Urologists' self-referral for pathology of biopsy specimens linked to increased use and lower prostate cancer detection. Health Aff (Millwood). 2012;31:741-749.

21. Ohsfeldt RL, Li P, Schneider JE. In-office magnetic resonance imaging (MRI) equipment ownership and MRI volume among medicare patients in orthopedic practices. Health Econ Rev. 2015;5:31.

22. Onega T, Hubbard R, Hill D, Lee CI, Haas JS, Carlos HA, Alford-Teaster J, Bogart A, DeMartini WB, Kerlikowske K, Kerlikowske K, Virnig BA, Buist DS, Henderson L, Tosteson AN. Geographic access to breast imaging for US women. $J$ Am Coll Radiol. 2014;11:874-882.

23. Patel BP, Levin DC, Parker L, Rao VM. The shift in outpatient advanced imaging from private offices to hospital facilities. $J \mathrm{Am}$ Coll Radiol. 2015;12:1042-1047.

24. Saper CB. The Affordable Care Act... or is it? Ann Neurol. 2015;78:155-157.

25. Schoen C, Lippa J, Collins S, Radley D. State trends in premiums and deductibles, 2003-2011: eroding protection and rising costs underscore need for action. Issue Brief (Commonw Fund). 2012;31:1-39.

26. Sistrom CL, McKay NL. Costs, charges, and revenues for hospital diagnostic imaging procedures: differences by modality and hospital characteristics. J Am Coll Radiol. 2005;2:511-519.

27. Sommers BD, Kronick R. The Affordable Care Act and insurance coverage for young adults. JAMA. 2012;307:913-914.

28. Sommers BD, Musco T, Finegold K, Gunja MZ, Burke A, McDowell AM. Health reform and changes in health insurance coverage in 2014. New Engl J Med. 2014;371:867-874.

29. Wharam JF, Ross-Degnan D, Rosenthal MB. The ACA and highdeductible insurance: strategies for sharpening a blunt instrument. New Engl J Med. 2013;369:1481-1484.

30. Willey JC, Reuter LS, Belatti DA, Phisitkul P, Amendola N. Availability of consumer

31. prices for bunion surgery. Foot Ankle Int. 2014; 35:1309-1315. 